\title{
Chemical and biomimetic total syntheses of natural and engineered MCoTI cyclotides
}

\author{
Panumart Thongyoo, ${ }^{a}$ Núria Roqué-Rosell, ${ }^{a}$ Robin J. Leatherbarrow ${ }^{* a}$ and Edward W. Tate ${ }^{* a}$ \\ Received (in XXX, XXX) 1st January 2007, Accepted 1st January 2007 \\ ${ }_{5}$ First published on the web 1st January 2007 \\ DOI: 10.1039/b000000x
}

The naturally-occurring cyclic cystine-knot microprotein trypsin inhibitors MCoTI-I and MCoTI-II have been synthesised using both thia-zip native chemical ligation and a biomimetic strategy featuring chemoenzymatic cyclisation by an immobilised protease. Engineered analogues have

10 been produced containing a range of substitutions at the $\mathrm{P}_{1}$ position that redirect specificity

towards alternative protease targets whilst retaining excellent to moderate affinity. Furthermore, we report an MCoTI analogue that is a selective low- $\mu \mathrm{M}$ inhibitor of foot-and-mouth-disease virus (FMDV) 3C protease, the first reported inhibitor of this important viral enzyme.

\section{Introduction}

${ }_{15}$ Cyclotides $^{1,2}$ are a unique class of head-to-tail cyclic cysteinerich microproteins up to 37 amino acids in length that exhibit a wide range of biological properties, ranging from anti-HIV ${ }^{3-}$ 5 to insecticidal activity. ${ }^{6,7}$ In contrast to many smaller naturally occurring cyclic peptides they are true gene 20 products, and possess a highly stable cystine-knot ${ }^{\dagger}$ topology, whereby two disulfide bridges form a ring through which a third is threaded. ${ }^{8-10}$ This combination of intricate structure, diverse biological activity and unusual biogenesis has inspired a growing research effort directed towards understanding the 25 synthesis and function of cyclotides both in the cell and in vitro. ${ }^{7,11-13}$ In addition, their high resistance to degradation in vivo has attracted recent and widespread interest in the potential of cyclotides as scaffolds to present structured protein domains for therapeutic applications. ${ }^{14-17}$ To date, 30 cyclotides have been isolated from a variety of plant species, including Cucurbitaceae (genus Momordica), ${ }^{18,19}$ Rubiaceae $^{20}$ and Violaceae, ${ }^{21,22}$ where they are thought to act as antifeedants. ${ }^{7}$ Recent work, most notably by the Craik group, has provided the three-dimensional structures of a wide range 35 of cyclotides by NMR. ${ }^{23}$ Syntheses of several small to medium size cyclotides have been reported ${ }^{24-28}$

The cyclotides MCoTI-I and MCoTI-II were first isolated from the dormant seeds of Momordica cochinchinensis, and have been shown to be very potent (sub-nM) inhibitors of ${ }_{40}$ trypsin. ${ }^{18}$ Whilst the MCoTI trypsin inhibitor cyclotides do not share significant sequence homology with other cyclotides beyond the presence of the three cystine bridges, solution NMR has shown that they do indeed adopt a backbone-cyclic cystine-knot topology (Fig. 1). The binding mode of these 45 cyclotides is likely to be similar to that of related cystine-knot trypsin inhibitors such as EETI; ${ }^{17,29,30}$ however, their rigidifying cyclic backbone contributes both enhanced stability and increased potency in comparison to these simpler structures.

50 As part of our ongoing studies on the potential of cyclotides as stable scaffolds for drugs or as tools for chemical genetics ${ }^{31}$ we wished to explore whether the structure of the MCoTI cyclotides may be re-engineered to exhibit novel inhibitory activity. Furthermore, previous studies suggest that cyclotides 55 from Rubiaceae and Violaceae form via protease-mediated ring closure at a conserved motif, ${ }^{7,12,32,33}$ and we hypothesised that the total synthesis of MCoTI cyclotides might be achieved via a biomimetic protease/ligase pathway. Here we report in full our recent studies in these two areas, ${ }^{34,35}$ and ${ }_{60}$ describe the activity and selectivity of natural and engineered MCoTI cyclotides for a range of proteases. We also discuss the potential implications for future work aimed at realising the full potential of cyclotides as tools in medicinal and chemical biology.
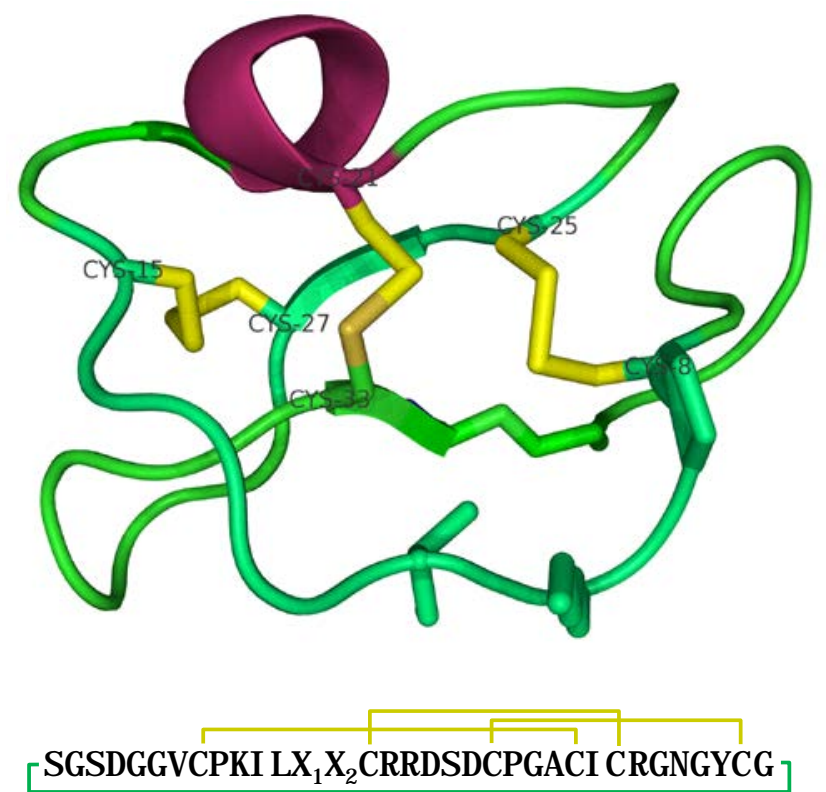

$$
\begin{array}{ll}
\text { MCOTI-II: } & X_{1}=X_{2}=K \\
\text { MCOTI-I: } & X_{1}=Q, X_{2}=R
\end{array}
$$

Figure 1 Solution NMR structure of MCoTI-II and sequences of the known naturally-occurring MCoTI cyclotides, MCoTI-I and -II. ${ }^{18,36}$ Key residues in the active loop (Pro9, Lys10, Ile11) and the cystine bridges are 
highlighted. Red: alpha helix; green: backbone; yellow: disulfide bridges. Structure rendered with PyMOL. ${ }^{37}$

\section{Results and Discussion}

\section{Chemical synthesis of engineered MCoTI cyclotides}

5 Total synthesis of an engineered cyclotide presents three key challenges:

1. Synthesis of the backbone, which in the case of MCoTI contains a sensitive Asp-Gly sequence.

102 . Head-to-tail backbone cyclisation.

3. Oxidative protein folding to form the three disulfide bonds in the correct cystine-knot geometry.

In practise, the strategy adopted for backbone synthesis lays 15 the foundation for correct cyclisation and folding, and this may be approached using a range of methodologies. Boc-, ${ }^{38}$ microwave-enhanced ${ }^{24}$ and Fmoc- ${ }^{14,30,34,35}$ based solid-phase peptide synthesis (SPPS) have all been used for cyclotide backbone construction, whilst recent work has shown that 20 bacterial expression can also be an effective approach for smaller scale production of the cyclotide backbone. ${ }^{25,28}$

Backbone cyclisation may then be achieved by exposing a suitably side chain protected backbone peptide bearing an amino N-terminus and a carboxy C-terminus to standard 25 peptide coupling conditions, but this approach suffers from multiple drawbacks including poor peptide solubility and the need for high dilution. Thia-zip native chemical ligation (TZNCL), a technique first pioneered by the Tam group, ${ }^{39,40}$ has emerged as the most effective method for backbone 30 cyclisation of cysteine-rich cyclic peptides, and is particularly applicable to the synthesis of cyclotides.
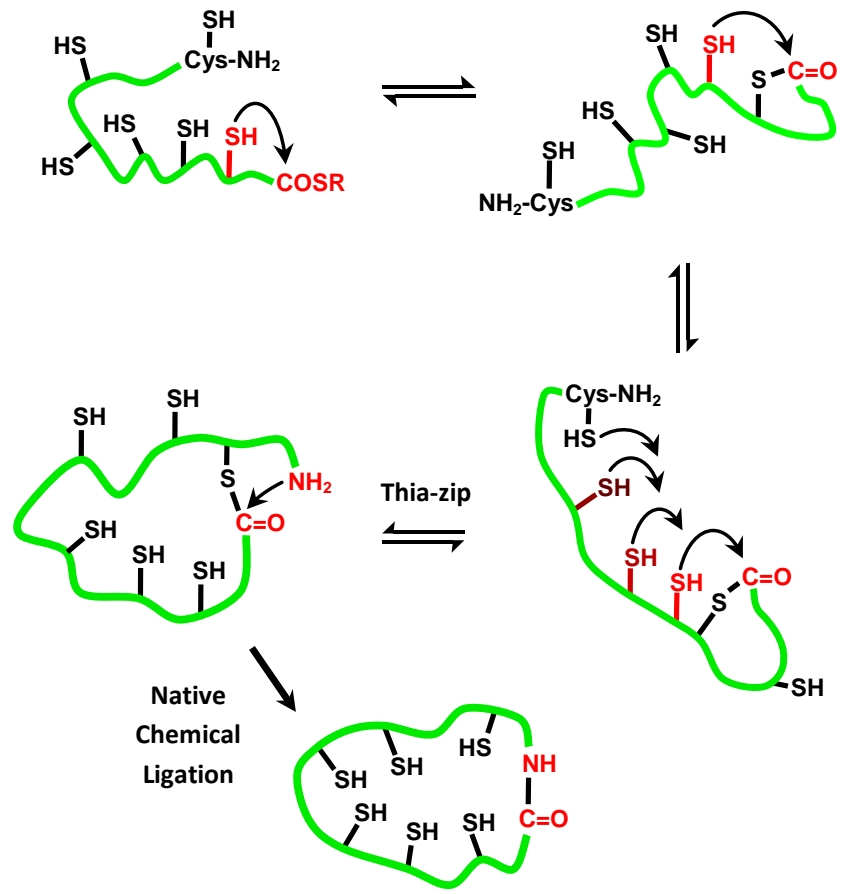

Scheme 1 Schematic representation of thia-zip native chemical ligation (TZ-NCL). Ring expansion occurs via an inter-converting series of
35 macrothiolactones, the largest of which can be trapped by an N-to-C rearrangement (NCL) to yield the target macrolactam.

In this approach, an unprotected backbone peptide bearing an N-terminal cysteine and a C-terminal thioester is simply dissolved in a suitable buffer triggering a spontaneous cascade 40 cyclisation reaction, resulting in eventual formation of a macrocyclic thioester that undergoes native chemical ligation to the target head-to-tail cyclic peptide (Scheme 1).The presence of multiple internal cysteine residues greatly accelerates the cyclisation by providing a series of thiolactone 45 intermediates of inferior ring size that are readily populated under equilibrium conditions, and are eventually converted into the target compound by irreversible macrolactamisation of the largest ring via NCL. Similarly, in the bacterial expression of cyclotides constructs bearing a C-terminal intein 50 permit a similar mechanism to operate. ${ }^{28}$ Despite the potentially problematic synthesis of a C-terminal thioester, the overall sequence of SPPS followed by TZ-NCL has proven to be significantly more efficient and reliable than the analogous peptide bond formation at high dilution, and may be 55 performed at relatively high concentration without detectable formation of oligomeric by-products.

Subsequent formation of the three disulfide bonds in the correct configuration is highly dependent on the inherent propensity of the cyclotide to adopt a cystine-knot. ${ }^{8}$ In some 60 cases, differential protection of cysteine residues with acetamidomethyl aminoacetal (Acm) groups is required to direct sequential formation of one or two disulfide bonds, followed by forced oxidation to the native state. $^{39}$ Unfortunately, this approach may reduce the efficiency of TZ${ }_{65}$ NCL due to reduced availability of internal cysteine residues, and disulfide bond exchange tends to reduce the purity of the final product. However, a recent systematic study on the mechanism of oxidative folding of plant-derived MCoTI-II by Craik et al. demonstrated that it has a strong tendency to 70 adopt the native cystine-knot conformation, ${ }^{9}$ so we did not anticipate significant problems with this step.

We therefore chose to adopt Fmoc-based SPPS synthesis of the backbone thioester followed by TZ-NCL for the total synthesis of MCoTI cyclotides and analogues. The Ala22${ }_{75}$ Cys23 amide bond was selected as the optimal position for backbone cyclisation, since among the possible Xaa-Cys disconnections it presents the lowest hindrance to NCL. SPPS was carried out on a sulfamylbutyryl 'safety-catch' linker ${ }^{41}$ after loading of the C-terminal alanine residue under 80 optimised conditions, as shown in Scheme 2. Activation and displacement of the resultant C-terminal sulphonamide was best achieved with iodoacetonitrile and ethyl 3-mercaptopropionate, resulting in excellent overall yield of linear thioester with respect to a sequence of $60+$ synthetic 85 steps. Introduction of the sensitive Asp-Gly motif as a dipeptide bearing a hydroxy-4-methoxybenzyl $(\mathrm{Hmb})^{42}$ protecting group on the glycine backbone nitrogen to suppress aspartimide formation was found to be essential, and omission of this group resulted in only trace quantities of linear product 90 from SPPS. 


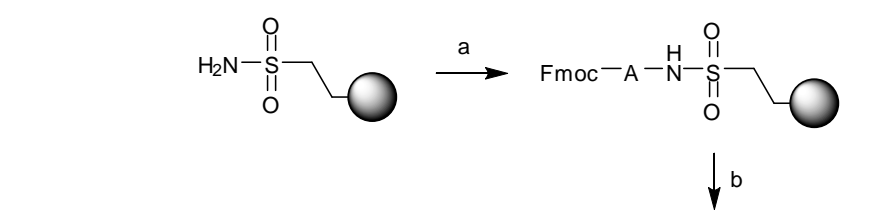

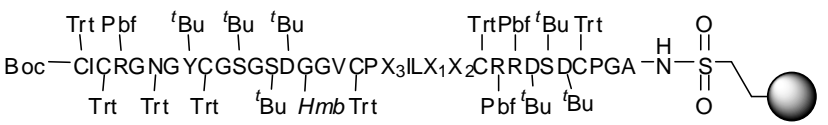

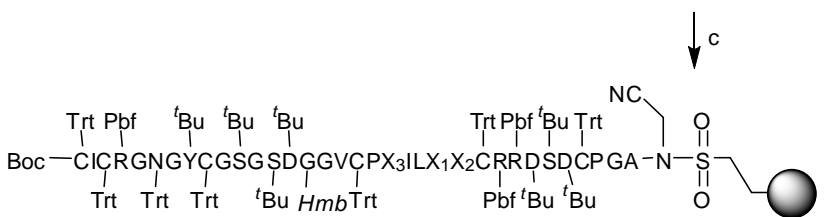
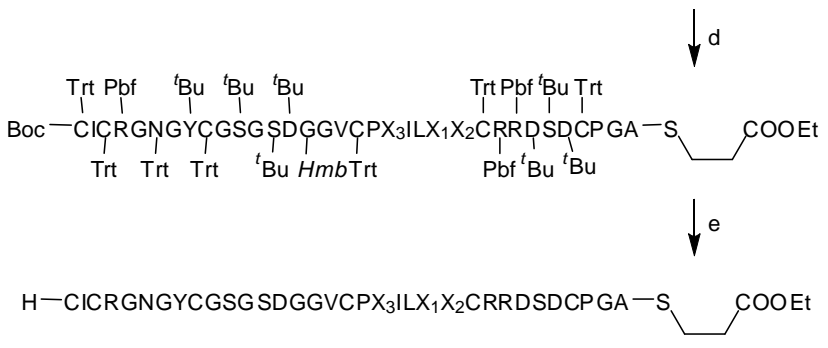

te-MCoTI analogues

Scheme 2 Synthetic route for SPPS synthesis of MCoTI cyclotide backbone thioester (te-MCoTI) analogues, starting from sulfamylbutyryl AM resin. MCoTI-I: $\mathrm{X}_{1}=\mathrm{Q}, \mathrm{X}_{2}=\mathrm{R}, \mathrm{X}_{3}=\mathrm{K}$; MCoTI-II: $\mathrm{X}_{1}=\mathrm{X}_{2}=\mathrm{X}_{3}=$

5 K; MCoTI-II analogues: $X_{1}=X_{2}=K, X_{3}=R, Q, F, V, A$ or AKQ. Protecting groups: Boc: tert-butyoxycarbonyl; Trt: trityl; Fmoc: 9-fluorenylmethoxycarbonyl; Pbf: 2,2,4,6,7-pentamethyl dihydrobenzo furan-5-sulfonyl; Hmb: hydroxy-4-methoxybenzyl (on backbone nitrogen). See Table 3 for overall yields of linear thioesters. Conditions:

10 a) Fmoc-Ala-OH, DIPEA, PyBOP, $-20{ }^{\circ} \mathrm{C}, 8 \mathrm{~h}$; b) Fmoc $/{ }^{\prime} \mathrm{Bu}$ SPPS; c) NMP, DIEPA, iodoacetonitrile (excess), 24 h, r.t.; d) sodium thiophenolate (cat.), ethyl 3-mercaptopropionate, DMF, 16 h, r.t.; e) TFA, $\mathrm{H}_{2} \mathrm{O}$, EDT, TIPS (94:2.5:2.5:1).

In addition to the naturally-occurring MCoTI-I and MCoTI15 II cyclotides, a focussed series of MCoTI-II analogues bearing alternative residues in place of Lys10 was designed to enable a systematic investigation of the influence of this position on protease inhibition. Lys10 is recognised as the key determinant of binding to trypsin by analogy to well20 characterised homologous cystine-knot trypsin inhibitors such as EETI, ${ }^{29,43}$ and occupies the $\mathrm{P}_{1}$ position in the substrate binding site. Engineering changes at this residue would therefore be expected to alter inhibitory activity against trypsin, and potentially enable the development of inhibitors

25 of alternative proteases whose activity depends on the presence of a residue other than Lys at $\mathrm{P}_{1}$, by analogy with previous work on peptide-based protease inhibitors. ${ }^{44-46}$ Accordingly, open chain thioester MCoTI-II analogues (teMCoTI) bearing positively charged (Arg), hydrophobic (Val, 30 Ala), aromatic (Phe) or amide (Gln) side chains were synthesised (Scheme 2b), along with one analogue with an expanded active loop (Ala-Lys-Gln) to investigate the versatility of the synthetic strategy with a longer backbone.

Backbone cyclisation of the linear thioesters via TZ-NCL 35 was achieved under standard NCL conditions (100 mM ammonium carbonate buffer, $\mathrm{pH} 7.5$ ), and in the presence of a reducing agent such as tricarboxyethyl phosphine (TCEP) the reduced cyclic backbone with six free cysteine thiols was isolated. Mild oxidative refolding by exposure to air in the 40 presence of a suitable disulfide bond-exchange mediator (glutathione, reduced form) resulted in smooth conversion to a new product within minutes, as determined by reverse-phase HPLC (RP-HPLC). Analysis of this material by MALDI-TOF showed the formation of 3 disulfide bonds, and the native 45 cyclotide fold of synthetic MCoTI-II was confirmed by NMR following the protocols of Craik et al., ${ }^{23}$ and in inhibition studies (see below). Optimal results were obtained by combining cyclisation and refolding in a one-pot reaction, whereby the linear thioester is treated with glutathione in the 50 same buffer, producing the target cyclotide in excellent overall yield (Scheme 3). The extended MCoTI-II variant MCoTI-II[AKQ] was formed in comparable yield and purity, suggesting that the MCoTI-II cyclotide fold tolerates the presence of additional residues in this loop.

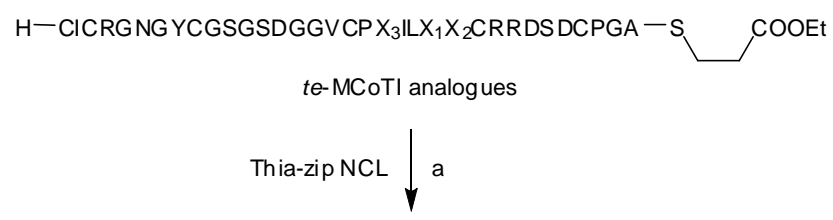

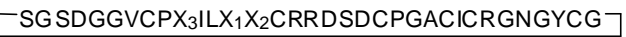

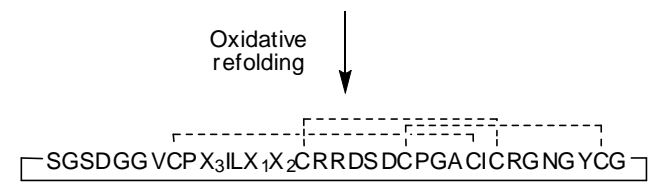

$55 \quad$ MCoTI analogues

Scheme 3 One-pot TZ-NCL-refolding of linear precursor thioester (teMCoTI) analogues; $\mathrm{X}_{1}, \mathrm{X}_{2}, \mathrm{X}_{3}$ : see Scheme 2. Solid bond: backbone cyclisation; dashed bonds: disulfide bridges. See Table 4 for isolated yield of target cyclotide after purification by RP-HPLC. Conditions: a) 60 glutathione $(1 \mathrm{mM}$, reduced form), aqueous ammonium carbonate (100 $\mathrm{mM}, \mathrm{pH}$ 7.4), r.t., 24 h. The intermediate head-to-tail cyclic peptide undergoes spontaneous refolding under these conditions to yield the target cyclotide in a one-pot reaction.

\section{Protease inhibition by engineered cyclotides}

${ }_{65}$ With a variety of natural and engineered MCoTI cyclotides in hand, we next analysed their activity against a panel of proteases (Table 1). As previously determined for the natural products, synthetic MCoTI-I and MCoTI-II are extremely potent trypsin inhibitors, with $K_{\mathrm{i}}$ values in the low-pM 70 range. $^{29}$ MCoTI-II[R], which contains a conservative substitution that is tolerated in trypsin substrates, also maintains the potency of the parent natural product. These cyclotides also proved to be highly selective for trypsin: all other analogues tested had $10^{3-4}$-fold lower activity in the 75 assay, emphasising the importance of a positively-charged residue at $\mathrm{P}_{1}$. Activity was effectively switched to chymotrypsin when Lys10 was changed to match the preferred $\mathrm{P}_{1}$ residue (Phe), with only MCoTI-II[F] showing low-nM activity against this enzyme, although other uncharged 80 residues $(\mathrm{Q}, \mathrm{V}, \mathrm{A})$ were also tolerated to some degree. The MCoTI cyclotides appear to be selective inhibitors for trypsin 
family proteases, exhibiting micromolar or higher $K_{\mathrm{i}}$ against the serine proteases thrombin and subtilisin. Remarkably however, MCoTI-II[Q] and MCoTI-II[AKQ] show significant activity against 3C protease from foot-and-mouth-disease 5 virus (FMDV 3C $\left.{ }^{\text {pro }}\right),{ }^{47}$ a recently identified cysteine protease essential for replication in this virulent pathogen. Inhibition is specific to these cyclotides, which contain elements of the preferred $\mathrm{P}_{4}-\mathrm{P}_{1}$ residues (PAKQ) of FMDV $3 \mathrm{C}^{\text {pro }}$, $^{48}$ with other cyclotide analogues showing no detectible activity. ${ }_{10}$ Crystallography studies have shown that FMDV $3 C^{\text {pro }}$, like other picornaviral cysteine proteases, exhibits structural homology to mammalian serine proteases including a chymotrypsin-like fold, which may favour the inhibitory activity of MCoTI cyclotides against this target. ${ }^{47,48}$ MCoTI$15 \mathrm{II}[\mathrm{Q}]$ and MCoTI-II[AKQ] represent the first known proteinbased inhibitors of this important viral protease.

Table 1 Inhibition activity $\left(K_{\mathrm{i}}\right)$ of naturally-occurring and engineered MCoTI cyclotides against trypsin, chymotrypsin, thrombin and FMDV $3 \mathrm{C}$ protease. Note that the units for activity against trypsin and 20 chymotrypsin are $\mathrm{pM}$ and $\mathrm{nM}$ respectively, and are $\mu \mathrm{M}$ for all other enzymes.

\begin{tabular}{|l|c|c|c|c|c|}
\hline \multirow{2}{*}{$\begin{array}{c}\text { Cyclotide } \\
\text { Lys10 }=[\mathbf{X}]\end{array}$} & $\begin{array}{c}\text { Trypsin } \\
(\mathrm{pM})\end{array}$ & $\begin{array}{c}\text { Chymo- } \\
\text { trypsin } \\
(\mathrm{nM})\end{array}$ & $\begin{array}{c}\text { Thrombin } \\
(\mu \mathrm{M})\end{array}$ & $\begin{array}{c}\text { Subtilisin } \\
(\mu \mathrm{M})\end{array}$ & $\begin{array}{c}\text { FMDV } \\
3 C^{\text {pro }} \\
(\mu \mathrm{M})\end{array}$ \\
\hline MCoTI-I & $\mathbf{2 9 \pm \mathbf { 2 }}$ & $>10^{4}$ & $>100$ & $>100$ & $>100$ \\
\hline MCoTI-II & $\mathbf{7 5 \pm \mathbf { 5 }}$ & $>10^{4}$ & $>100$ & $>100$ & $>100$ \\
\hline MCoTI-II[R] & $\mathbf{8 5} \pm \mathbf{7}$ & $>10^{4}$ & $>100$ & $>100$ & $>100$ \\
\hline MCoTI-II[Q] & $5 \times 10^{6}$ & $2 \times 10^{3}$ & $>100$ & $>100$ & $\mathbf{4 1} \pm \mathbf{2 5}$ \\
\hline MCoTI-II[F] & $0.4 \times 10^{6}$ & $\mathbf{9 . 8} \pm \mathbf{0 . 7}$ & $>100$ & $\mathbf{4 9} \pm \mathbf{4}$ & $>100$ \\
\hline MCoTI-II[V] & $>10^{9}$ & $>10^{4}$ & $>100$ & $>100$ & $>100$ \\
\hline MCoTI-II[A] & $>10^{9}$ & $>10^{4}$ & $>100$ & $>100$ & $>100$ \\
\hline MCoTI-II [AKQ] & $>10^{9}$ & $>10^{4}$ & $>100$ & $>100$ & $\mathbf{5 6} \pm \mathbf{3 5}$ \\
\hline
\end{tabular}

${ }^{a}$ Footnote text.

\section{Chemoenzymatic synthesis of engineered MCoTI cyclotides}

25 Having established the inhibition activity and selectivity profile of the MCoTI cyclotides, we next sought to design a simplified synthesis of the head-to-tail cyclic cystine-knot scaffold by utilising a biomimetic (chemoenzymatic) approach. It is known that related cyclic peptidic trypsin 30 inhibitors such as BPTI ${ }^{49,50}$ and SFTI-I ${ }^{51}$ bind to the enzyme active site in an inter-convertible mixture of non-covalent enzyme-peptide complex and covalently-bound peptidylenzyme, a non-productive analogue of the acyl-enzyme intermediate in proteolytic cleavage. Building on previous 35 work that shows that proteases can be induced to synthesise a peptide bond by careful control of the reaction conditions, ${ }^{52-55}$ we reasoned that a linear cyclotide backbone acid bearing the $\mathrm{P}_{1}$ residue at the $\mathrm{C}$-terminus might be a viable substrate for protease-mediated ligation, thus enabling synthesis of the 40 cyclic backbone without the need for a C-terminal thioester.

An initial proof-of-principle experiment was carried out to test whether this concept could be applied for total synthesis of the naturally-occurring MCoTI-II. The requisite Lys10 C- terminal acid open-chain backbone (oc-MCoTI-II) was ${ }_{45}$ synthesised in excellent overall yield using $\mathrm{Fmoc} /{ }^{t} \mathrm{Bu}$ SPPS. As in our previous syntheses of MCoTI cyclotides, aspartimide formation at the DG motif was effectively suppressed by the introduction of $\mathrm{Hmb}$ protection at the glycine backbone nitrogen. ${ }^{42}$ oc-MCoTI-II was refolded to the 50 cystine-knot peptide $r f$-MCoTI-II by exposure to our standard oxidative refolding conditions (Scheme 4), and no misfolded peptide was observed by HPLC. In initial attempts to achieve backbone ligation, mixtures of $r f$-MCoTI-II and trypsin (up to $1: 1$ ratio) were combined in $100 \mathrm{mM}$ phosphate buffer ( $\mathrm{pH}$ 55 7.4). In each case, some cyclisation to MCoTI-II was seen by MALDI and HPLC by comparison with authentic MCoTI-II prepared by one-pot TZ-NCL chemistry, but contamination with peptides resulting from protease auto-digestion precluded further analysis and purification.
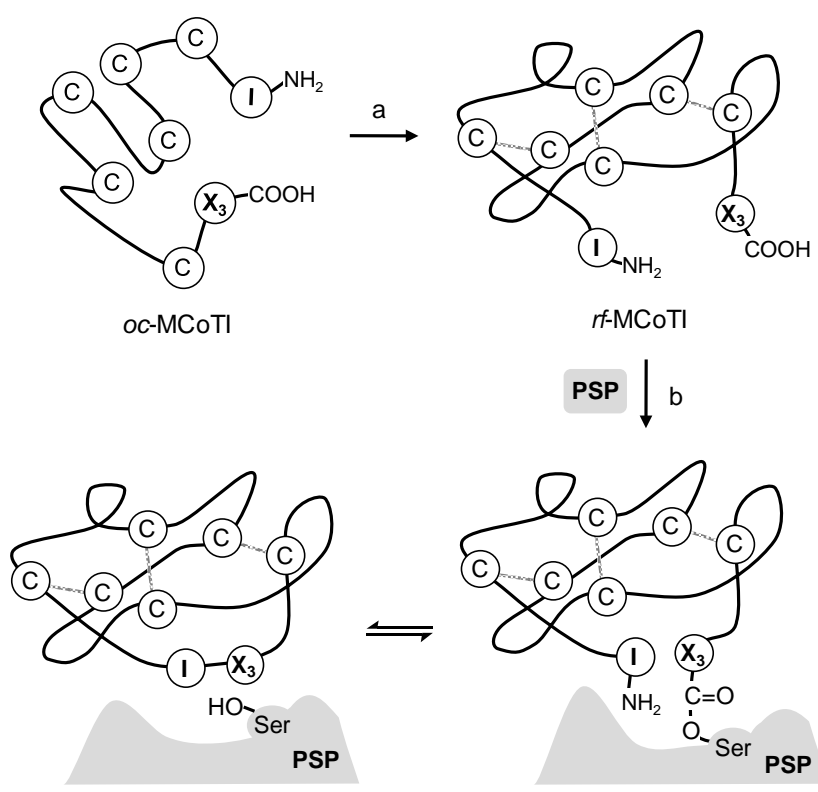

MCoTI:PSP complex

MCoTI-PSP peptidyl-enzyme

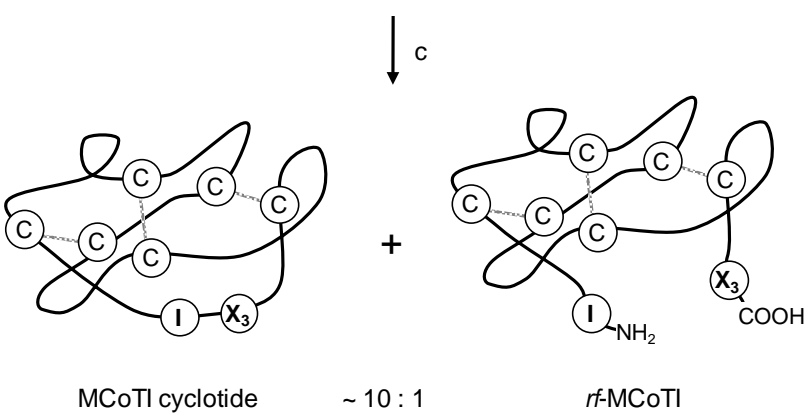

Scheme 4 Chemoenzymatic synthesis of MCoTI-II and analogues from open-chain acids (oc-MCoTI, prepared by SPPS), via refolded cystineknot intermediates ( $r f$-MCoTI). PSP: polymer supported serine protease (trypsin or chymotrypsin); $\mathrm{X}_{3}=\mathrm{K}$ or $\mathrm{F}$. Conditions: a) $0.1 \mathrm{M}$ ammonium 65 carbonate ( $\mathrm{pH} 7.8$ )/acetonitrile 1:1, $1 \mathrm{mM}$ glutathione (reduced form); b) PSP (1 equiv.), $100 \mathrm{mM}$ sodium phosphate ( $\mathrm{pH} 7.0)$; c) wash $\left(\mathrm{H}_{2} \mathrm{O}\right)$, then $0.1 \% \mathrm{TFA}_{(\mathrm{aq})}$.

Trypsin immobilised on Sepharose beads (polymersupported trypsin, PST) is used widely for sequencing 70 applications, since contamination through autocleavage is 
greatly suppressed. We considered that PST might be employed as a polymer-supported ligase for clean MCoTI macrolactamisation. Furthermore, the newly formed cyclotide should remain tightly bound to the solid support, enabling 5 facile in situ affinity purification. ${ }^{\ddagger}$ In a typical binding procedure (Scheme 4) a two-fold excess of $r f$-MCoTI-II was incubated with sequencing grade PST suspended in phosphate buffer (100 mM, pH 7.4) at $37^{\circ} \mathrm{C}$ for $15 \mathrm{~min}$, after which the beads were washed several times with buffer. We 10 hypothesised that increased protonation at the trypsin active site might result in release of the cyclotide from the putative cyclotide-enzyme complex in a non-denaturing and $\mathrm{pH}$ dependent manner, and thus allow the relatively costly PST to be recycled. Gratifyingly, upon treatment with $0.1 \%$ aqueous 15 TFA ( $\mathrm{pH} 3$ ) in deionised water MCoTI-II was released from PST in 92\% yield, and in high purity (Figure 2). MCoTI-II synthesised by this chemoenzymatic method was identical in all respects to naturally occurring MCoTI-II. ${ }^{18,19,29,36}$ Interestingly, concomitant release of a small amount (8\%) of $20 \mathrm{rf}$-MCoTI-II is observed, although it was absent from the flow-through from the wash steps. Incubating pure MCoTI-II with PST under the same conditions yielded an identical mixture, strongly suggesting that this $\sim 10$ :1 ratio reflects the equilibrium mixture of MCoTI-II-trypsin complex to peptidyl25 enzyme intermediate, similar to that previously noted by Craik et al. in related studies on SFTI-I. ${ }^{51}$ It was found that by virtue of the non-denaturing elution conditions, PST could be reused in at least five cycles of protease-mediated ligation with no detectable loss of activity. In summary, PST-mediated 30 ligation effectively combines macrolactamisation with onbead affinity purification; the cyclotide is bound as a $1: 1$ trypsin-cyclotide complex, as evidenced by the ability of MCoTI-II to titrate the trypsin active site, necessitating a stoichiometric quantity of PST relative to $r f$-MCoTI-II. 35 Remarkably, backbone refolding and PST-mediated ligation/affinity purification may even be combined in a single pot by simple incubation of crude oc-MCoTI-II with PST in buffer containing $1 \mathrm{mM}$ glutathione to give MCoTI-II and $\sim 10 \%$ residual $r f$-MCoTI-II in very high purity upon elution 40 with $0.1 \%$ TFA.

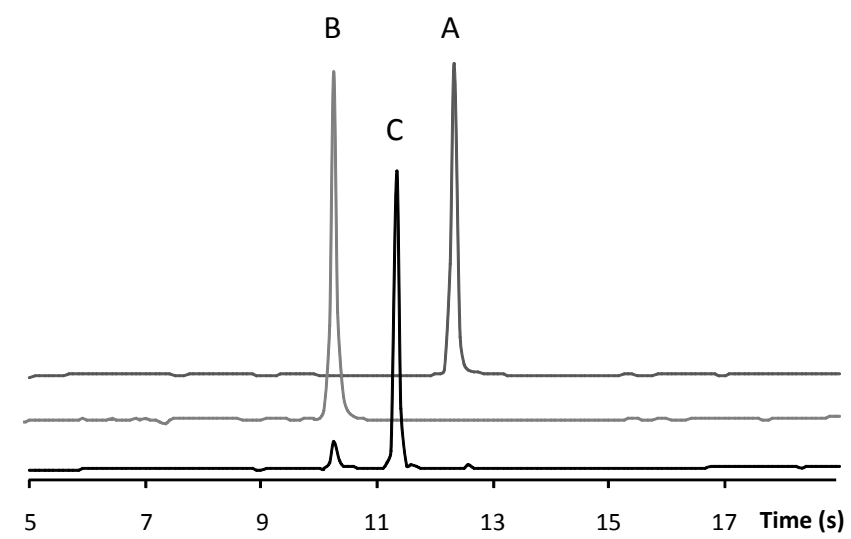

Figure 2 HPLC traces showing conversion of open-chain acid to refolded backbone to target cyclotide. A: purified oc-MCoTI-II; B: purified $r f$ MCoTI-II; C: product after elution of MCoTI-II from PST with $0.1 \%$
$45 \mathrm{TFA}_{(\mathrm{aq})}$. Gradient: 0 to $85 \% \mathrm{MeCN}$ in $\mathrm{H}_{2} \mathrm{O}(+0.1 \% \mathrm{TFA})$ over 40 minutes.

This facile new route to MCoTI-II was explored in a series of experiments that show that PST possesses ligase specificity for positively charged (Arg/Lys) residues at $\mathrm{P}_{1}$ in the 50 inhibitory loop. The open-chain forms of the naturally occurring cyclotide MCoTI-I ( $\left.\mathrm{P}_{1}=\mathrm{Lys}\right)$ and three MCoTI-II analogues in which $\mathrm{P}_{1}$ was changed to Arg, Gln or Phe (Table 2) were synthesised by SPPS, and subjected to the refolding and PST-mediated ligation conditions described above. ${ }_{55}$ Folded macrocyclic MCoTI-I and MCoTI-II[R] were produced in high purity by comparison with authentic samples prepared by TZ-NCL, whilst MCoTI-II[Q] and MCoTI-II[F] appear to be cleaved at one or more positions on the backbone, with multiple peaks observed in the RP-HPLC 60 trace. As for MCoTI-II, ligation reactions yielded MCoTI-I (93\%) and MCoTI-II[R] (94\%) together with refolded starting material in a 10:1 ratio. However, re-engineering the inhibitory loop to contain $\mathrm{P}_{1}=\mathrm{Phe}$ enables ligation by chymotrypsin. Thus oc-MCoTI-II[F] was refolded and 65 incubated with commercially available sequencing-grade polymer-supported chymotrypsin (PSC) to yield MCoTI-II[F] analogue cyclotide (90\%), with $10 \%$ residual $r f$-MCoTI-II[F]. Furthermore, the reaction is highly specific: $r f$-MCoTI-II[F] is the only MCoTI analogue susceptible to ligation with PSC; 70 other cyclotides are either unreactive or partially digested under the same conditions. Qualitative selectivity in the ligase reaction is therefore directly related to potency of inhibition: only the most potent inhibitory cyclotides are susceptible to ligation with a given solid-supported protease.

75 Table 2 Yield of cyclotides and intermediates synthesised by SPPS, refolding and protease-mediated backbone ligation.

\begin{tabular}{|l|c|c|c|c|}
\hline \multirow{2}{*}{$\begin{array}{c}\text { Cyclotide } \\
\text { Lys10 }=[\mathrm{X}]\end{array}$} & \multicolumn{4}{|c|}{ Yield (\%) } \\
\cline { 2 - 5 } & $\begin{array}{c}\text { SPPS } \\
\text { oc-Cyclotide }\end{array}$ & $\begin{array}{c}\text { Refolding } \\
r f-C y c l o t i d e\end{array}$ & $\begin{array}{c}\text { PST } \\
\text { Cyclotide }\end{array}$ & $\begin{array}{c}\text { PSC } \\
\text { Cyclotide }\end{array}$ \\
\hline MCoTI-I & 7 & 72 & $93^{a}$ & 0 \\
\hline MCoTI-II & 8 & 65 & $92^{a}$ & 0 \\
\hline MCoTI-II[R] & 13 & 59 & $94^{a}$ & $0^{b}$ \\
\hline MCoTI-II[F] & 5 & 64 & $0^{b}$ & $90^{a}$ \\
\hline MCoTI-II[Q] & 10 & 60 & $0 \mathrm{~b}$ & 0 \\
\hline
\end{tabular}

${ }^{a}$ In each case, residual $r f$-cyclotide was returned in 7-10\% yield after in situ affinity purification. ${ }^{b}$ Starting material partially digested.

\section{Conclusions}

80 In summary, we have achieved the total synthesis of MCoTI-I, MCoTI-II and MCoTI cyclotide analogues in a strategy that combines optimised SPPS of the peptide backbone bearing an $\mathrm{N}$-terminal cysteine and C-terminal thioester, native chemical ligation/cyclisation via an efficient thia-zip reaction, and ${ }_{85}$ refolding under mild conditions to yield the native cystineknot topology. At up to 36 residues in size, these compounds are among the largest synthetic cyclotides reported to date, and their syntheses demonstrate the versatility and efficiency of this synthetic approach. Furthermore, we have developed a 90 biomimetic strategy for the synthesis of MCoTI cyclotides bearing a Lys10 or Phe10 residue, utilising commercially available polymer-supported proteases that can act as a ligase 
for the refolded cyclotide backbone. This chemoenzymatic approach displays even greater efficacy than the nonenzymatic route described above, and provides for in situ affinity purification of the target cyclotides. The ease with 5 which oc-MCoTI analogues fold and ligate in the presence of an appropriate protease raises the possibility that biosynthesis of MCoTI cyclotides might follow a protease/ligase pathway in vivo, in a similar manner to the structurally related Kalata cyclotide family. ${ }^{32}$

${ }_{10}$ To realise the full potential of cyclotides as stable scaffolds for drugs and as tools for chemical genetics it is necessary to demonstrate that their structure may be re-engineered without loss of activity. We have reported here the first instance of redesigning the active loop of a cyclotide to redirect its 15 specificity towards alternative targets whilst retaining moderate to high affinity. Proteases are of central importance as current and potential drug targets in a wide range of diseases. Foot-and-mouth disease, a disease of cloven-hoofed livestock, exacts a severe economic toll on affected 20 communities. ${ }^{56}$ In the work presented here, the first cyclotide inhibitors of the foot-and-mouth viral 3C protease are reported, ${ }^{48,57}$ based on a re-engineered MCoTI-II cyclotide scaffold. Though the potency of these first generation inhibitors is moderate (low $\mu \mathrm{M}$ ), it is notable that cyclotides 25 based on a trypsin inhibitor scaffold exhibit activity against this cysteine protease.

We anticipate that the efficient chemical and chemoenzymatic routes presented here will be readily adapted to ligation, screening and in situ purification of cyclotide30 based libraries. ${ }^{2,26}$ In particular, polymer-supported proteases represent a potentially powerful platform for screening combinatorial libraries of precursor peptides for sequences that can adopt a native cyclotide fold, and for the identification of novel cyclotide-based protease inhibitors 35 with inherent stability in vivo. ${ }^{17,58}$

\section{Experimental}

\section{Materials and Methods}

All general laboratory chemicals obtained from chemical suppliers (Novabiochem UK or Sigma-Aldrich Chemical Co.) 40 were used without further purification. Peptides were synthesised using an Advanced ChemTech Apex 396 multiple peptide synthesiser (Advanced Chemtech Europe, Cambridge, UK). Purification of crude peptides was performed on a Gilson semi-preparative RP-HPLC system (Anachem Ltd., 45 Luton, UK) equipped with 306 pumps and a Gilson 155 UV/Vis detector. Analytical RP-HPLC was performed on a Gilson analytical HPLC system (Anachem Ltd., Luton, UK) equipped with a Gilson $151 \mathrm{UV} / \mathrm{Vis}$ detector and Gilson 234 auto injector, on a C-18 stationary phase. Peptide purification 50 was achieved using preparative reverse-phase HPLC using a HICHROM C18 Column $(250 \times 21.2 \mathrm{~mm})$. For both HPLC systems, the peptide bond absorption was detected at $223 \mathrm{~nm}$. The following elution methods were used: Method A: 20 to $50 \% \mathrm{MeCN}$ in $\mathrm{H}_{2} \mathrm{O}$ over $40 \mathrm{~min}$; Method B: 0 to $85 \% \mathrm{MeCN}$ 55 in $\mathrm{H}_{2} \mathrm{O}$ over $40 \mathrm{~min}$. The mobile phases contained $0.1 \%$ HPLC-grade TFA as an ion pairing agent and were degassed with helium. All peptides and reaction mixtures were analysed using Method B unless otherwise specified. Solid phase resins, preloaded Wang resin and 4-sulfamylbutyryl AM resin, 60 were purchased from Novabiochem UK. The resin loadings were as follows: Fmoc-Lys(Boc)-Wang : $0.69 \mathrm{mmol} / \mathrm{g}$; FmocPhe-Wang : $0.74 \mathrm{mmol} / \mathrm{g} ;$ Fmoc-Gln(Trt)-Wang : 0.62 $\mathrm{mmol} / \mathrm{g} ; \quad$ Fmoc-Arg(Pbf)-Wang : $0.51 \mathrm{mmol} / \mathrm{g} ; \quad 4-$ sulfamylbutyryl AM resin : $1.1 \mathrm{mmol} / \mathrm{g}$. Amino acids: $\mathrm{N}-\alpha-9-$ 65 Fluorenylmethoxycarbonyl (N- $\alpha$-Fmoc) protected amino acid were obtained from Novabiochem UK with the following side-chain protecting groups. Ala, $\operatorname{Arg}(\mathrm{Pbf}), \mathrm{Asn}(\mathrm{Trt})$, Asp(tBu), Cys(Trt), Gly, Ile, Leu, Lys(Boc), Pro, Ser $\left({ }^{\mathrm{t} B u}\right)$, Tyr $\left({ }^{t} \mathrm{Bu}\right), \quad$ Val and Fmoc-Asp $\left(\mathrm{O}^{t} \mathrm{Bu}\right)-(\mathrm{Hmb}) \mathrm{Gly}-\mathrm{OH}$ were 70 purchased from Novabiochem UK. Reagents: Peptide synthesis grade dimethylformamide (DMF) from Rathburn Chemicals UK. Benzotriazole-1-yl-oxy-tris-pyrrolidinophosphonium hexafluorophosphate (PyBOP), Nhydroxybenzotriazole (HOBt), diisopropylethylamine 75 (DIPEA) and 2-(1H-benzotriazole-1-yl)-1,1,3,3tetramethylaminium hexafluorophosphate (HBTU) were purchased from Novabiochem UK and Sigma-Aldrich. Dry tetrahydrofuran (THF) and $N, N$-dimethylsulfoxide (DMF), chloroform, dimethylsulfoxide (DMSO), dichloromethane 80 (DCM), $N$-methyl pyrrolidone (NMP), methanol, piperidine, thioanisole, $t$-butylmethylether (TBME), trifluoroacetic acid (TFA), ethanedithiol (EDT), iodoacetonitrile, 3-mercaptoethyl propionate, sodium thiophenolate, monobasic and dibasic sodium phosphate, and trimethylsilylisopropane (TIPS) were 85 regent grade from Sigma-Aldrich. A 'deprotection mixture' of TFA: $\mathrm{H}_{2} \mathrm{O}$ :EDT:TIPS (94:2.5:2.5:1) was used for cleavage and deprotection reactions.

\section{General procedures}

Loading of sulfamylbutyryl AM resin with Fmoc-Ala-OH: 90 Sulfamylbutyryl AM resin (250 mg, $0.172 \mathrm{mmol}$ ) was swollen in DMF (3 $\mathrm{mL}$ ) for 1 hour at ambient temperature. To this solution were added Fmoc-Ala-OH (268 mg, $0.86 \mathrm{mmol}$ ) and DIPEA (264 $\mu \mathrm{L}, 1.6 \mathrm{mmol})$. The reaction mixture was left to stir for 15 minutes followed by cooling to $-20{ }^{\circ} \mathrm{C}$ for 20 95 minutes. Then PyBOP (447 mg, $0.86 \mathrm{mmol}$ ) was added and the reaction mixture stirred for 8 hours at $-20{ }^{\circ} \mathrm{C}$. The reaction mixture was left to warm to ambient temperature overnight. The resin was recovered by filtration and washed with DMF $(3 \times 2 \mathrm{~mL})$. The coupling was repeated using the same 100 procedure and washed with DMF $(3 \times 2 \mathrm{~mL}), \operatorname{DCM}(3 \times$ $2 \mathrm{~mL})$ and $\mathrm{MeOH}(3 \times 2 \mathrm{~mL})$, respectively. The loaded resin was dried in vacuo. The coupling efficiency was assessed as follows: typically $2 \mathrm{mg}$ of thoroughly-dried resin (or peptidyl resin) was incubated with a solution of $1 \mathrm{~mL} 20 \%$ piperidine 105 in DMF, and left for 1 hour. The solution was then filtered off and the filtrate measured for its absorbance at $290 \mathrm{~nm}$ or $301 \mathrm{~nm}\left(\varepsilon_{290 \mathrm{~nm}}=5800 \mathrm{M}^{-1} \mathrm{~cm}^{-1}, \varepsilon_{301 \mathrm{~nm}}=7800 \mathrm{M}^{-1} \mathrm{~cm}^{-1}\right)$ against a blank of $20 \%$ piperidine in DMF. Loading efficiency was $~ 81 \%$.

${ }_{110}$ Solid Phase Peptide Synthesis: Peptide synthesis was carried out in peptide synthesis grade DMF. Resin preloaded with appropriate amino acid (25 $\mu$ mol per well) was swelled in DMF for 60 minutes before each coupling cycle, $\mathrm{N}$ - $\alpha$-amino 
Fmoc group was removed with $20 \%(\mathrm{v} / \mathrm{v})$ piperidine in DMF for 15 minutes, with two further repetitions. A fivefold excess of amino acid over resin reactive groups $(125 \mu \mathrm{mol}, 250 \mu \mathrm{L}$ of a $0.5 \mathrm{M}$ solution) was used for each coupling. In situ 5 activation and coupling was carried out for 45 min with a mixture of HBTU/HOBt $(125 \mu$ mole, $250 \mu \mathrm{L}$ of a $0.5 \mathrm{M}$ solution) and DIPEA (125 $\mu$ mole, $250 \mu \mathrm{L}$ of $0.5 \mathrm{M}$ solution). The peptide was washed with DMF $(3 \times 1 \mathrm{~mL})$ between each deprotection and coupling step. A typical cycle consisted of 10 deprotection, DMF wash, coupling and a further DMF wash. The $\mathrm{N}-\alpha$-Fmoc protection at the final residue was removed at the end of the synthesis under the usual conditions. After synthesis was complete, the fully protected resin-bound MCoTI was removed from the synthesiser, washed several 15 times ( $3 \times 2 \mathrm{~mL} \mathrm{DMF,} 3 \times 2 \mathrm{~mL}$ DCM, $3 \times 2 \mathrm{~mL} \mathrm{MeOH})$ and dried in vacuo. Asp7Gly6 was introduced as a dipeptide (Fmoc-Asp(O $\mathrm{O}^{\mathrm{Bu}}$ )-(Hmb)Gly-OH) and coupled for 2 hours. Cys34 was introduced as Boc-Cys(Trt)-OH for te-MCoTI syntheses. Residues were double-coupled where appropriate 20 (see Table 3).

Activation and displacement from sulfamyl resin: Activation: fully protected MCoTI bound to sulfamyl resin (25 $\mu \mathrm{mol}$ ) was swelled in $1.5 \mathrm{~mL}$ of dry NMP for 1 hour. To this solution was added DIEPA $(200 \mu \mathrm{L}, 1.1 \mathrm{mmol})$ followed 25 by excess iodoacetonitrile $(180 \mu \mathrm{L}$ filtered through basic alumina prior to use). The reaction flask was shielded from light and agitated for 24 hours at ambient temperature. The resin was washed with NMP $(5 \times 5 \mathrm{~mL})$, DCM $(5 \times 5 \mathrm{~mL})$, $\mathrm{MeOH}(5 \times 5 \mathrm{~mL})$ and dried in vacuo. Displacement: to the 30 activated resin were added a small amount of sodium thiophenolate $(1.6 \mathrm{mg})$, ethyl 3-mercaptopropionate $(160 \mu \mathrm{L}$, $1.25 \mathrm{mmol})$ and DMF $(500 \mu \mathrm{L})$. The reaction mixture was agitated overnight at ambient temperature. The resin was filtered and the filtrate was evaporated to dryness in vacuo to 35 yield fully protected MCoTI thioester which was subsequently treated with $2 \mathrm{~mL}$ of deprotection mixture over 3 hours to give the corresponding te-MCoTI. Precipitation and purification were conducted as described below.

Deprotection and cleavage from Wang resin: Cleavage and 40 deprotection of peptides was achieved by adding $1.5 \mathrm{~mL}$ of deprotection mixture to dry peptide bound resin $(25 \mu \mathrm{mol})$. The mixture was agitated on an orbital shaker for up to 3 hours and then filtered. The resin was washed twice with a small volume of TFA and the combined washings and filtrate 45 were precipitated with $10 \mathrm{~mL}$ ice cold TBME. The mixture was centrifuged at $5000 \mathrm{rpm}$ for 20 minutes at $0^{\circ} \mathrm{C}$, the supernatant discarded and the remaining peptide washed with a fresh aliquot of TBME. The process was repeated three times to ensure complete removal of all organic impurities. 50 The crude peptide was dried in a desiccator over silica gel to yield an off-white solid.

Peptide Purification: A small sample of crude peptide was analysed by analytical preparative RP-HPLC before purifying by preparative HPLC. Individual fractions from preparative 55 reverse-phase HPLC were analysed using analytical reversephase HPLC, and pure fractions combined and diluted to $<10 \% \mathrm{MeCN}$ with deionised water. The peptide was obtained as a white solid after lyophilisation on a Christ Alpha 2-4 freeze dryer (Osterode am Harz Germany). Mass 60 identification by Matrix-Assisted Laser Desorption/Ionisation Time of Flight Mass spectrometry (MALDI-TOF MS) was performed using $\alpha$-Cyano-4-hydroxycinnamic acid as the matrix.

Synthesis of cyclotides via thia-zip native chemical ${ }_{65}$ ligation: Glutathione $(0.3 \mathrm{mg}, 1 \mu \mathrm{mol})$ was dissolved in $1 \mathrm{~mL}$ of $0.1 \mathrm{M}$ carbonate buffer. This solution was added to teMCoTI $(0.28 \mu \mathrm{mol})$ which was dissolved in $1 \mathrm{~mL}$ of acetonitrile and the reaction mixture left for 24 hours at room temperature. The reaction mixture was then diluted 2-fold in 70 water and purified by preparative RP-HPLC using Method A. Fractions were collected, analysed by analytical HPLC, pure fractions pooled and lyophilized to yield the product cyclotide.

Synthesis of $r$-MCoTI-I, II and analogues via oxidative 75 refolding: $o c$-MCoTI acid $(0.28 \mu \mathrm{mol})$ was dissolved in $1 \mathrm{~mL}$ of $0.1 \mathrm{M}$ ammonium carbonate buffer. To this solution was added glutathione $(0.3 \mathrm{mg}, 1 \mu \mathrm{mol})$, which was dissolved in acetonitrile $(1 \mathrm{~mL})$. The reaction mixture was allowed to stand for 48 hours at room temperature, diluted two-fold with water 80 and purified by RP-HPLC using Method A. Fractions were collected, analysed using Method B, pooled and lyophilised.

Synthesis of cyclotides via ligation by immobilised protease: Cyclisation using immobilised trypsin: Immobilised trypsin ( $500 \mu \mathrm{L}$ of re-suspended beads) was washed with 0.1 ${ }_{85} \mathrm{M}$ phosphate buffer $(5 \times 1 \mathrm{~mL}, \mathrm{pH} 7.4)$ before use. $r$-MCoTI peptide $(0.03 \mu \mathrm{mol})$ was dissolved in $500 \mu \mathrm{L} 0.1 \mathrm{M}$ phosphate buffer $\mathrm{pH} 7.4$ and added to immobilised trypsin. The reaction mixture was incubated at $37^{\circ} \mathrm{C}$ for 15 minutes, mixed on a vortex mixer for $10 \mathrm{~s}$ and centrifuged at $14000 \mathrm{rpm}$ for 5 90 minutes. The supernatant was removed from immobilised trypsin which was subsequently washed with water $(5 \times$ $1 \mathrm{~mL}$ ); the reaction mixture was mixed and centrifuged as above at each washing. $0.1 \%$ TFA in water was added and the mixture mixed and left to stand for 5 minutes, the supernatant 95 was recovered, and this procedure was repeated. The combined TFA washings were analysed by analytical HPLC and MALDI-MS. Cyclisation using immobilised chymotrypsin: The reaction was performed exactly as for immobilised trypsin, except that $25 \mathrm{mg}$ immobilised 100 chymotrypsin was weighed out and washed as above.

Peptide concentration determination for MCoTI-I, II and MCoTI-II[R]: The concentration of active MCoTI cyclotide was determined by titration with trypsin (adapted from Ref. 12). Microprotein at a range of concentrations $(1 \mu \mathrm{M}$ to $1050.1 \mathrm{nM}, 50 \mu \mathrm{L}$ ) in TBS pH 7.6 (Tris buffered saline: $50 \mathrm{mM}$ Tris.HCl, $150 \mathrm{mM} \mathrm{NaCl,} 0.01 \%$ Tritron ${ }^{\circledR}$ X-100, $0.02 \%$ sodium azide) was incubated with trypsin $(25 \mathrm{nM}, 50 \mu \mathrm{L})$ for 30 minutes at $37{ }^{\circ} \mathrm{C}$ in a 96-well plate (Falcon Microtest ${ }^{\mathrm{TM}}$ 96). Carbobenzoxy-L-arginine-7-amino-4-methyl coumarin $110(75 \mu \mathrm{M}, 100 \mu \mathrm{L})$ was added to the solution and the absorbance measured at room temperature with excitation and emission wavelengths at 360 and $465 \mathrm{~nm}$ respectively. The concentration of active cyclotide was determined from inhibition curves obtained in two separate experiments 115 assuming a 1:1 interaction between inhibitor and trypsin.

Peptide concentration determination for MCoTI-II[F] and 
MCoTI-II[Q]: These MCoTI-II analogues have relatively low inhibition activity against trypsin, and so a standard addition method was used to determine peptide concentration using analytical HPLC. A standard addition graph from MCoTI-I, II 5 and MCoTI-II[R] was plotted by varying the active peptide concentration ( $200 \mu \mathrm{M}$ to $10 \mu \mathrm{M})$ versus peak area measured at $223 \mathrm{~nm}$ and, by comparison of peak areas, used to determine the concentration of microproteins MCoTI-II[F] and MCoTI-II[Q].

10 Inhibition Kinetics: All inhibition kinetics were determined by competitive binding assays at $37^{\circ} \mathrm{C}$ on a Cytofluor series 400 microplate reader (Perseptive Biosystem, Warrington, UK), using Falcon Microtest ${ }^{\mathrm{TM}}$ 96-well plates. TBS pH 7.6 was prepared for trypsin and chymotrypsin assays. The 15 equilibrium dissociation constant $\left(K_{\mathrm{i}}\right)$ for the complex between trypsin or chymotrypsin and the cyclotide was determined by using enzyme concentrations lower than the $K_{i}$. Thus, proteases $(0.005 \mathrm{nM}, 50 \mu \mathrm{L}$ trypsin or $0.5 \mathrm{nM}, 50 \mu \mathrm{L}$ chymotrypsin, $12.5 \mu \mathrm{M}, 50 \mu \mathrm{L}$ subtilisin and $1 \mathrm{nM}, 50 \mu \mathrm{L}$ 20 thrombin) were incubated at a suitable range of concentrations of inhibitor in TBS for 1 hour. The measurement was started by the addition of substrate: $(5 \mu \mathrm{M}, 100 \mu \mathrm{L} N$-p-tosyl-GlyPro-Arg-AMC (AMC: 7-amido-4-methyl coumarin) for trypsin and thrombin assays, or succinimidyl-Ala-Ala-Pro25 Phe-AMC $(10 \mu \mathrm{M}, 100 \mu \mathrm{L}$ for chymotrypsin or $19 \mu \mathrm{M}$, $100 \mu \mathrm{L}$ for subtilisin assays). The initial rate of substrate hydrolysis was monitored by the cleavage of AMC from substrate at an excitation of $360 \mathrm{~nm}$ and emission of $460 \mathrm{~nm}$. Cyclotide activity against FMDV $3 C^{\text {pro }}$ was determined as 30 described previously, using $617 \mathrm{nM}, 50 \mu \mathrm{L}$ FMDV $3 C^{\text {pro }}, 50$ $\mu \mathrm{M}, 100 \mu \mathrm{L}$ FRET substrate. ${ }^{59}$ Initial rate data were then fitted to determine $K_{\mathrm{i}}$ using the GraFit Software package (http://www.erithacus.com/grafit). All assays were reproduced 3 times with fresh solutions of all reagents, and the standard 35 deviation is given where appropriate.

\section{Additional Characterisation Data}

Table 3 Open-chain acids (oc-) and thioesters (te-) synthesised by SPPS.

\begin{tabular}{|l|c|c|c|c|}
\hline \multirow{2}{*}{$\begin{array}{c}\text { Cyclotide } \\
\text { Lys10 = [X] }\end{array}$} & \multicolumn{3}{|c|}{ Data } \\
\cline { 2 - 5 } & $\begin{array}{c}\text { Residues } \\
\text { double- } \\
\text { coupled }\end{array}$ & Yield & MALDI-MS & $\begin{array}{c}\text { Retention } \\
\text { time (min) } \\
\text { (Method B) }\end{array}$ \\
\hline oc-MCoTI-I & $\begin{array}{c}\text { Ala21 } \\
\text { Gly22 }\end{array}$ & $7 \%$ & $\begin{array}{c}3507[\mathrm{M}+\mathrm{H}]^{+} \\
1754[\mathrm{M}+2 \mathrm{H}]^{2+}\end{array}$ & 12.4 \\
\hline oc-MCoTI-II & $\begin{array}{c}\text { Ala21 } \\
\text { Gly22 } \\
\text { Ile34 }\end{array}$ & $8 \%$ & $3478[\mathrm{M}+\mathrm{H}]^{+}$ & 12.3 \\
\hline oc-MCoTI-II[R] & $\begin{array}{c}\text { Ala21 } \\
\text { Gly22 } \\
\text { Ile34 }\end{array}$ & $13 \%$ & $\begin{array}{c}3505[\mathrm{M}+\mathrm{H}]^{+} \\
1753[\mathrm{M}+2 \mathrm{H}]^{2+}\end{array}$ & 12.0 \\
\hline oc-MCoTI-II[F] & $\begin{array}{c}\text { Ala21 } \\
\text { Gly22 } \\
\text { Ile34 }\end{array}$ & $10 \%$ & $3497[\mathrm{M}+\mathrm{H}]^{+}$ & 14.4 \\
\hline oc-MCoTI-II[Q] & $\begin{array}{c}\text { Ala21 } \\
\text { Gly22 } \\
\text { Ile34 }\end{array}$ & $5 \%$ & $\begin{array}{c}3478[\mathrm{M}+\mathrm{H}]^{+} \\
1739[\mathrm{M}+2 \mathrm{H}]^{2+}\end{array}$ & 12.3 \\
\hline te-MCoTI-I & $\begin{array}{c}\text { Ala21 } \\
\text { Gly22 } \\
\text { Ile34 }\end{array}$ & $5 \%$ & $3676[\mathrm{M}+\mathrm{H}]^{+}$ & 10.2 \\
\hline te-MCoTI-II & $\begin{array}{c}\text { Val18 } \\
\text { Lle14 } \\
\text { Lys15 }\end{array}$ & $6 \%$ & $3622[\mathrm{M}+\mathrm{H}]^{+}$ & 14.8 \\
\hline
\end{tabular}

\begin{tabular}{|l|c|c|c|c|}
\hline & Val18 & & & \\
\hline te-MCoTI-II[R] & $\begin{array}{c}\text { Ile14 } \\
\text { Arg15 }\end{array}$ & $7 \%$ & $3622[\mathrm{M}+\mathrm{H}]^{+}$ & 14.1 \\
\hline te-MCoTI-II[F] & $\begin{array}{c}\text { Ile14 } \\
\text { Phe15 }\end{array}$ & $4 \%$ & $\begin{array}{c}3613[\mathrm{M}+\mathrm{H}]^{+} \\
1807[\mathrm{M}+2 \mathrm{H}]^{2+}\end{array}$ & 15.4 \\
\hline te-MCoTI-II[Q] & $\begin{array}{c}\text { Ile14 } \\
\text { Gln15 }\end{array}$ & $4 \%$ & $\begin{array}{c}3593[\mathrm{M}+\mathrm{H}]^{+} \\
1797[\mathrm{M}+2 \mathrm{H}]^{2+}\end{array}$ & 14.6 \\
\hline te-MCoTI-II[V] & $\begin{array}{c}\text { Ile14 } \\
\text { Val15 }\end{array}$ & $4 \%$ & $\begin{array}{c}3566[\mathrm{M}+\mathrm{H}]^{+} \\
1783[\mathrm{M}+2 \mathrm{H}]^{2+}\end{array}$ & 14.6 \\
\hline te-MCoTI-II[A] & $\begin{array}{c}\text { Ile14 } \\
\text { Ala15 }\end{array}$ & $4 \%$ & $\begin{array}{c}3537[\mathrm{M}+\mathrm{H}]^{+} \\
1769[\mathrm{M}+2 \mathrm{H}]^{2+}\end{array}$ & 14.7 \\
\hline te-MCoTI-II[AKQ] & $\begin{array}{c}\text { Ile14 } \\
\text { Gln15 } \\
\text { Lys16 } \\
\text { Ala17 }\end{array}$ & $5 \%$ & $\begin{array}{c}3793[\mathrm{M}+\mathrm{H}]^{+} \\
1897[\mathrm{M}+2 \mathrm{H}]^{2+}\end{array}$ & 14.5 \\
\hline
\end{tabular}

Table 4 Open-chain refolded ( $r f$-) cyclotides synthesised by oxidative refolding and cyclotides synthesised by TZ-NCL and/or immobilised 40 protease-mediated ligation.

\begin{tabular}{|l|c|c|c|}
\hline \multicolumn{1}{|c}{$\begin{array}{c}\text { Cyclotide } \\
\text { Lys10 = [X] }\end{array}$} & Yield & MALDI-MS & $\begin{array}{c}\text { Retention time } \\
\text { (min) } \\
\text { (Method B) }\end{array}$ \\
\cline { 2 - 4 } & $72 \%$ & $3501[\mathrm{M}+\mathrm{H}]^{+}$ & 10.5 \\
\hline rf-MCoTI-I & $65 \%$ & $\begin{array}{c}3472[\mathrm{M}+\mathrm{H}]^{+} \\
1737[\mathrm{M}+2 \mathrm{H}]^{2+}\end{array}$ & 10.4 \\
\hline rf-MCoTI-II & $59 \%$ & $\begin{array}{c}3500[\mathrm{M}+\mathrm{H}]^{+} \\
1751[\mathrm{M}+2 \mathrm{H}]^{2+}\end{array}$ & 10.5 \\
\hline rf-MCoTI-II[R] & $60 \%$ & $\begin{array}{c}3491[\mathrm{M}+\mathrm{H}]^{+} \\
1746[\mathrm{M}+2 \mathrm{H}]^{2+}\end{array}$ & 12.2 \\
\hline rf-MCoTI-II[F] & $64 \%$ & $\begin{array}{c}3473[\mathrm{M}+\mathrm{H}]^{+} \\
1736[\mathrm{M}+2 \mathrm{H}]^{2+}\end{array}$ & 10.6 \\
\hline rf-MCoTI-II [Q] & $68 \%^{a}$ & $\begin{array}{c}3482[\mathrm{M}+\mathrm{H}]^{+} \\
1741[\mathrm{M}+2 \mathrm{H}]^{2+}\end{array}$ & 12.3 \\
\hline rf-MCoTI-II[AKQ] & $72 \%^{a}$ & $\begin{array}{c}3454[\mathrm{M}+\mathrm{H}]^{+} \\
1727[\mathrm{M}+2 \mathrm{H}]^{2+}\end{array}$ & 11.5 \\
\hline MCoTI-I & $72 \%^{a}$ & $\begin{array}{c}3483[\mathrm{M}+\mathrm{H}]^{+} \\
1742[\mathrm{M}+2 \mathrm{H}]^{2+}\end{array}$ & 11.8 \\
\hline MCoTI-II & $64 \%^{a}$ & $\begin{array}{c}3474[\mathrm{M}+\mathrm{H}]^{+} \\
1737[\mathrm{M}+2 \mathrm{H}]^{2+}\end{array}$ & 15.2 \\
\hline MCoTI-II[R] & $64 \%^{a}$ & $\begin{array}{c}3427[\mathrm{M}+\mathrm{H}]^{+} \\
1713[\mathrm{M}+2 \mathrm{H}]^{2+}\end{array}$ & 10.2 \\
\hline MCoTI-II[F] & $63 \%^{a}$ & $\begin{array}{c}3399[\mathrm{M}+\mathrm{H}]^{+} \\
1699[\mathrm{M}+2 \mathrm{H}]^{2+}\end{array}$ & 10.1 \\
\hline MCoTI-II[V] & $71 \%^{a}$ & $\begin{array}{c}3653[\mathrm{M}+\mathrm{H}]^{+} \\
1827[\mathrm{M}+2 \mathrm{H}]^{2+}\end{array}$ & 11.7 \\
\hline MCoTI-II[A] & $\begin{array}{c}3482[\mathrm{M}+\mathrm{H}]^{+} \\
1742[\mathrm{M}+2 \mathrm{H}]^{2+}\end{array}$ & 12.4 \\
\hline MCoTI-II[AKQ] & $\begin{array}{c}3454[\mathrm{M}+\mathrm{H}]^{+} \\
1728[\mathrm{M}+2 \mathrm{H}]^{2+}\end{array}$ & 11.4 \\
\hline MCoTI-I & $90 \%^{b}$ & $\begin{array}{c}3481[\mathrm{M}]^{+} \\
1741[\mathrm{M}+2 \mathrm{H}]^{2+}\end{array}$ & 11.8 \\
\hline MCoTI-II & $3474[\mathrm{M}+\mathrm{H}]^{+}$ & 15.4 \\
\hline MCoTI-II[F] & 32.0 & \\
\hline
\end{tabular}

${ }^{a}$ Synthesised by TZ-NCL; ${ }^{b}$ synthesised by immobilised proteasemediated ligation.

\section{Notes and references}

$45{ }^{a}$ Department of Chemistry, Imperial College London, Exhibition Rd., London SW7 2AZ. Fax: (+44) (0)2075941139. E-mail:

e.tate@imperial.ac.uk; r.leatherbarrow@imperial.ac.uk.

We are grateful to the the BBSRC for a David Phillips Research Fellowship (to EWT), the Royal Thai Government for a research 
studentship (to PT), and the European Union for Marie Curie Host Fellowships for Early Stage Research Training (to NR and PT).

$\dagger$ Note that the term cysteine-knot is also used to describe this structural motif.

$5 \ddagger$ Subsequent to our first communication of the work presented here, PST was also described as a reagent for affinity purification of MCoTI-II expressed in E. coli. ${ }^{25}$

1. D. J. Craik, M. Cemazar and N. L. Daly, Curr. Opin. Drug Discov. Devel., 2007, 10, 176-184.

10 2. D. J. Craik, M. Cemazar, C. K. Wang and N. L. Daly, Biopolymers, 2006, 84, 250-266.

3. D. C. Ireland, C. K. Wang, J. A. Wilson, K. R. Gustafson and D. J. Craik, Biopolymers, 2007.

4. K. R. Gustafson, T. C. McKee and H. R. Bokesch, Curr. Protein

15 Pept. Sci., 2004, 5, 331-340.

5. N. L. Daly, K. R. Gustafson and D. J. Craik, FEBS Lett., 2004, 574, 69-72.

6. C. V. Jennings, K. J. Rosengren, N. L. Daly, M. Plan, J. Stevens, M. J. Scanlon, C. Waine, D. G. Norman, M. A. Anderson and D. J.

20 Craik, Biochemistry, 2005, 44, 851-860.

7. C. Jennings, J. West, C. Waine, D. Craik and M. Anderson, Proc. Natl. Acad. Sci. USA, 2001, 98, 10614-10619.

8. D. J. Craik and N. L. Daly, Protein Pept. Lett., 2005, 12, 147-152.

9. M. Cemazar, N. L. Daly, S. Haggblad, K. P. Lo, E. Yulyaningsih and

25 D. J. Craik, J. Biol. Chem., 2006, 281, 8224-8232.

10. K. J. Rosengren, N. L. Daly, M. R. Plan, C. Waine and D. J. Craik, J. Biol. Chem., 2003, 278, 8606-8616.

11. P. Seydel, C. W. Gruber, D. J. Craik and H. Dornenburg, Appl. Microbiol. Biotechnol., 2007, 77, 275-284.

30 12. A. D. Gillon, I. Saska, C. V. Jennings, R. F. Guarino, D. J. Craik and M. A. Anderson, Plant J., 2007.

13. D. J. Craik, D. G. Barry, R. J. Clark, N. L. Daly and L. Sando, J. Toxicol., Toxin Rev., 2003, 22, 555-576.

14. T. Leta Aboye, R. J. Clark, D. J. Craik and U. Goransson, 35 ChemBioChem, 2007.

15. D. J. Craik, M. Cemazar and N. L. Daly, Curr. Opin. Drug Discov. Devel., 2006, 9, 251-260.

16. D. J. Craik, S. Simonsen and N. L. Daly, Curr. Opin. Drug Discov. Devel., 2002, 5, 251-260.

40 17. M. Werle, K. Kafedjiiski, H. Kolmar and A. Bernkop-Schnurch, Int J Pharm, 2007, 332, 72-79.

18. M. E. Felizmenio-Quimio, N. L. Daly and D. J. Craik, J. Biol. Chem., 2001, 276, 22875-22882.

19. J. F. Hernandez, J. Gagnon, L. Chiche, T. M. Nguyen, J. P. Andrieu,

45 A. Heitz, T. Trinh Hong, T. T. Pham and D. Le Nguyen, Biochemistry, 2000, 39, 5722-5730.

20. D. J. Craik, N. L. Daly, T. Bond and C. Waine, J. Mol. Biol., 1999, 294, 1327-1336.

21. S. M. Simonsen, L. Sando, D. C. Ireland, M. L. Colgrave, R.

50 Bharathi, U. Goransson and D. J. Craik, Plant cell, 2005, 17, 31763189.

22. M. Trabi and D. J. Craik, Plant cell, 2004, 16, 2204-2216.

23. D. J. Craik and N. L. Daly, Mol. Biosyst., 2007, 3, 257-265.

24. M. Cemazar and D. Craik, in J. Pept. Sci., 2008.

55 25. J. A. Camarero, R. H. Kimura, Y. H. Woo, A. Shekhtman and J. Cantor, ChemBioChem, 2007, 8, 1363-1366.
26. J. A. Camarero, R. H. Kimura, Y. H. Woo, J. Cantor and E. Steenblock, Chim. Oggi, 2007, 25, 20-23.

27. S. Gunasekera, N. L. Daly, M. A. Anderson and D. J. Craik, IUBMB $60 \quad$ life, 2006, 58, 515-524.

28. R. H. Kimura, A. T. Tran and J. A. Camarero, Angew. Chem. Int. Ed. Engl., 2006, 45, 973-976.

29. O. Avrutina, H. U. Schmoldt, D. Gabrijelcic-Geiger, D. Le Nguyen, C. P. Sommerhoff, U. Diederichsen and H. Kolmar, Biol. Chem.,

$65 \quad$ 2005, 386, 1301-1306.

30. O. Avrutina, H. U. Schmoldt, H. Kolmar and U. Diederichsen, Eur. J. Org. Chem., 2004, 4931-4935.

31. E. W. Tate, Signal Transduction, 2006, 6, 144-159.

32. I. Saska, A. D. Gillon, N. Hatsugai, R. G. Dietzgen, I. Hara-

70 Nishimura, M. A. Anderson and D. J. Craik, J. Biol. Chem., 2007, 282, 29721-29728.

33. C. W. Gruber, M. Cemazar, R. J. Clark, T. Horibe, R. F. Renda, M. A. Anderson and D. J. Craik, J. Biol. Chem., 2007.

34. P. Thongyoo, E. W. Tate and R. J. Leatherbarrow, Chem. Commun., 2006, 2848-2850.

35. P. Thongyoo, A. M. Jaulent, E. W. Tate and R. J. Leatherbarrow, ChemBioChem, 2007, 8, 1107-1109.

36. A. Heitz, J. F. Hernandez, J. Gagnon, T. T. Hong, T. T. Pham, T. M. Nguyen, D. Le-Nguyen and L. Chiche, Biochemistry, 2001, 40, 7973807983.

37. W. L. DeLano, The PyMOL molecular graphics system, http://www.pymol.org.

38. J. P. Tam, Y. A. Lu, J. L. Yang and K. W. Chiu, Proc. Natl. Acad. Sci. USA, 1999, 96, 8913-8918.

85 39. J. P. Tam and Y. A. Lu, Protein Sci., 1998, 7, 1583-1592.

40. J. P. Tam and Y. A. Lu, Tetrahedron Lett., 1997, 38, 5599-5602.

41. P. Heidler and A. Link, Bioorg. Med. Chem., 2005, 13, 585-599.

42. R. G. Simmonds, Int. J. Pept. Protein Res., 1996, 47, 36-41.

43. H. H. Niemann, H. U. Schmoldt, A. Wentzel, H. Kolmar and D. W.

$90 \quad$ Heinz, J. Mol. Biol., 2006, 356, 1-8.

44. J. D. McBride and R. J. Leatherbarrow, Curr. Med. Chem., 2001, 8, 909-917.

45. J. D. McBride, E. M. Watson, A. B. Brauer, A. M. Jaulent and R. J. Leatherbarrow, Biopolymers, 2002, 66, 79-92.

95 46. D. Scarpi, J. D. McBride and R. J. Leatherbarrow, J. Pept. Res., 2002, 59, 90-93.

47. T. R. Sweeney, N. Roque-Rosell, J. R. Birtley, R. J. Leatherbarrow and S. Curry, J. Virol., 2007, 81, 115-124.

48. S. Curry, N. Roque-Rosell, P. A. Zunszain and R. J. Leatherbarrow, $100 \quad$ Int. J. Biochem. Cell Biol., 2007, 39, 1-6.

49. C. Groeger, H. R. Wenzel and H. Tschesche, Angew. Chem. Int. Ed. Engl., 1993, 32, 898-900.

50. C. Groeger, H. R. Wenzel and H. Tschesche, Int. J. Pept. Protein Res., 1994, 44, 166-172.

105 51. U. C. Marx, M. L. Korsinczky, H. J. Schirra, A. Jones, B. Condie, L. Otvos, Jr. and D. J. Craik, J. Biol. Chem., 2003, 278, 21782-21789.

52. R. V. Ulijn, B. Baragana, P. J. Halling and S. L. Flitsch, J. Am. Chem. Soc., 2002, 124, 10988-10989.

53. R. V. Ulijn, N. Bisek, P. J. Halling and S. L. Flitsch, Org. Biomol. $110 \quad$ Chem., 2003, 1, 1277-1281.

54. D. Y. Jackson, J. Burnier, C. Quan, M. Stanley, J. Tom and J. A. Wells, Science, 1994, 266, 243-247. 
55. D. Y. Jackson, J. P. Burnier and J. A. Wells, J. Am. Chem. Soc., 1995, 117, 819-820.

56. P. Kitching, J. Hammond, M. Jeggo, B. Charleston, D. Paton, L. Rodriguez and R. Heckert, Vaccine, 2007, 25, 5660-5664.

5 57. S. Curry, N. Roque-Rosell, T. R. Sweeney, P. A. Zunszain and R. J. Leatherbarrow, Biochem Soc. Trans., 2007, 35, 594-598.

58. K. P. Greenwood, N. L. Daly, D. L. Brown, J. L. Stow and D. J. Craik, Int. J. Biochem. Cell Biol., 2007, 39, 2252-2264.

59. A. M. Jaulent, A. S. Fahy, S. R. Knox, J. R. Birtley, N. Roque-Rosell,

10 S. Curry and R. J. Leatherbarrow, Anal. Biochem., 2007, 368, 130137. 